\title{
Clinical assessment and polysomnographic study of sleep apnea in a Chinese population of snorers*
}

\author{
Chuan SHAO ${ }^{\dagger}$, Jing-bo JIANG ${ }^{\dagger \ddagger}$, Hong-cheng WU, Shi-bo WU, Bi-yun YU, Yao-dong TANG \\ (Department of Respiratory Medicine, Ningbo Medical Treatment Center Lihuili Hospital, Ningbo 315040, China) \\ †E-mail: shaochuan1984@sina.cn; docjjb1015@126.com \\ Received Aug. 30, 2014; Revision accepted Jan. 4, 2015; Crosschecked Feb. 16, 2015
}

\begin{abstract}
Background and objectives: While an increasing number of people who snore are seeking medical consultations, the clinical characteristics of snorers are rarely reported. The aim of this study is to characterize the clinical and polysomnographic features in a population of snorers. Methods: A total of 490 subjects were examined retrospectively. The clinical history, Epworth Sleepiness Scale (ESS) scores, physical examination, and full-night polysomnography (PSG) data were obtained for all the subjects. The correlations between the neck circumference, waist circumference, ESS scores, body mass index (BMI), and apnea-hypopnea index (AHI) of obstructive sleep apnea (OSA) patients were explored. The gender and age differences in OSA patients were analyzed. Results: OSA was diagnosed in $84.7 \%$ of the sample, with $21.2 \%$ of the patients having a mild form, $15.4 \%$ having a moderate form, and $63.4 \%$ having a severe form of OSA. The ESS scores, neck circumference, waist circumference, and BMI were positively correlated with $\mathrm{AHI}$ in OSA patients. The ESS scores and BMI were negatively correlated with nadir oxygen saturation $\left(\mathrm{SaO}_{2}\right)$. A greater number of men than women exhibited moderate to severe forms of the disease. OSA affects the work of males more commonly compared with females. Nocturia was a more common complaint in elderly OSA patients. Heart diseases coexisted more frequently with OSA in elderly patients. Conclusions: In a population of snorers, OSA is the most common condition identified. The ESS scores and BMI were well correlated with the severity of the disease. Men had a more severe form of OSA than women. Nocturia frequently occurred in elderly OSA patients, as did the coexistence of heart disease.
\end{abstract}

Key words: Obstructive sleep apnea, Gender, Elderly, Hypoxia, Snoring doi: $10.1631 /$ jzus.B1400236

Document code: A

CLC number: R56

\section{Introduction}

The number of people seeking medical consultations for snoring is increasing. Obstructive sleep apnea (OSA) is the most common sleep-disordered breathing. In view of the obesity pandemic, the incidence of OSA is likely to rise (Jordan et al., 2014). The prevalence of symptomatic OSA in the general population is $2 \%-4 \%$, and OSA increases with age (de Backer, 2013). OSA is associated with a number of adverse outcomes, including sleep disruption,

\footnotetext{
¿ Corresponding author

* Project supported by the Ningbo Natural Science Foundation of China (No. 2013A610236)

(iD) ORCID: Chuan SHAO, http://orcid.org/0000-0001-9073-219X

(C) Zhejiang University and Springer-Verlag Berlin Heidelberg 2015
}

cognitive dysfunction, traffic accidents, and increased risk of cardiovascular diseases. OSA has become a global health problem, and it reduces the quality of life and increases mortality.

The objectives of this study are to examine the clinical characteristics and polysomnographic outcomes in a population of snorers. The OSA patients were further studied for factors that might be related to the severity of the disease. The gender and age differences in OSA were assessed as well.

\section{Materials and methods}

\subsection{Subjects}

A total of 490 snorers, who were admitted to the hospital and underwent a full-night polysomnography 
(PSG) during January 2013 to April 2014, were enrolled as subjects in this study. None of the subjects were referred because of a previous diagnosis and treatment for OSA, and the PSG tests of all the subjects were valid.

The access to patient records was approved by the local ethics committee, and patient confidentiality was maintained.

\subsection{Clinical assessment}

The anthropometric data including gender, age, height, weight, body mass index (BMI), neck circumference, and waist circumference and the detailed clinical data including the symptoms, comorbidities, Epworth Sleepiness Scale (ESS) scores, and physical examination records focusing on the maxillofacial, oropharynx, and neck regions were recorded. Excessive daytime sleepiness was assessed by an ESS score of $>10$.

\subsection{Sleep study}

The full-night PSG recordings were reviewed independently by two sleep specialists. A polysomnographic system (Alice 5, Respironics, Philips, Pittsburgh, Pennsylvania, USA) was used to perform the PSG tests. The diagnosis of OSA was confirmed following the criteria proposed by the adult OSA task force of the American Academy of Sleep Medicine (Epstein et al., 2009).

\subsection{Statistical analyses}

The characteristics of the subjects were summarized as the mean \pm standard deviation (SD) for the continuous variables and as counts and percentages for the categorical variables. Pearson's or Spearman's correlation analysis was used to explore the correlations between the neck circumference, waist circumference, ESS scores, BMI and AHI in the OSA patients. An independent $t$-test or one-way analysis of variance (ANOVA) was used for the comparison between the groups of continuous variables, and a Chi-squared test or Fisher's exact test was used for the categorical variables. A binary logistic regression analysis was used to compare the clinical data of the gender and age groups. In all the cases, $P<0.05$ was considered statistically significant. All the statistical analyses were performed using SPSS, Version 20.0 (SPSS, Inc., Chicago, IL, USA).

\section{Results}

\subsection{General sample}

A total of 409 males and 81 females were analyzed with an age of $(45.27 \pm 11.6)$ years; 460 patients were young and middle-aged ( $<65$ years), and 30 patients were elderly ( $\geq 65$ years). OSA was identified in $415(84.7 \%)$ patients, simple snoring in $65(13.3 \%)$, mixed sleep apnea (MSA) in $6(1.2 \%)$, and central sleep apnea (CSA) in $4(0.8 \%)$.

In the 409 male patients, OSA was identified in 362 patients $(88.5 \%)$, simple snoring in $39(9.5 \%)$, MSA in $4(1.0 \%)$, and CSA in $4(1.0 \%)$. In the 81 female patients, OSA was identified in $53(65.4 \%)$ patients, simple snoring in $26(32.1 \%)$, MSA in 2 $(2.5 \%)$, and CSA in $0(0 \%)$. Gender $(84.7 \%)$ differences existed for the prevalence of various forms of sleepdisordered breathing (Fisher's exact test, $P<0.001$ ).

In the 460 young and middle-aged patients, OSA was identified in $390(84.8 \%)$ patients, simple snoring in $62(13.5 \%)$, MSA in $4(0.9 \%)$, and CSA in $4(0.9 \%)$. In the 30 elderly patients, OSA was identified in 25 $(83.3 \%)$ patients, simple snoring in $3(10.0 \%)$, MSA in $2(6.7 \%)$, and CSA in $0(0 \%)$. The prevalence of various forms of sleep-disordered breathing was similar in the age groups.

\subsection{Characteristics of OSA patients}

Of the 415 OSA patients, 362 patients were male, 53 were female, 390 were young and middle-aged, and 25 were elderly.

In addition to snoring, the majority of the OSA patients had other symptoms; 171 (41.2\%) patients complained of gasping/choking at night, 66 (15.9\%) of morning headaches, 265 (63.9\%) of dry mouth, $242(58.3 \%)$ of daytime sleepiness, $121(29.2 \%)$ of nocturia, $252(60.7 \%)$ of memory loss, and 174 $(41.9 \%)$ of irritability. OSA influenced the quality of life in 168 patients $(40.5 \%)$, affected the patient's work in $121(29.2 \%)$, and had an effect on traffic safety in $62(14.9 \%)$ patients. The mean ESS score was $7.88 \pm 4.66$, and 130 (31.3\%) OSA patients had ESS scores of $>10$.

Among the OSA patients, 154 (37.1\%) had comorbidity with hypertension, $54(13.0 \%)$ with diabetes mellitus, $45(10.8 \%)$ with heart disease, 7 (1.7\%) with cerebrovascular disease, 26 (6.3\%) with reflux esophagitis, $15(3.6 \%)$ with thyroid diseases, 
159 (38.3\%) with rhinitis, 180 (43.4\%) with pharyngolaryngitis, and $14(3.4 \%)$ patients had a history of upper airway surgery.

A number of OSA patients had signs of upper airway narrowing as follows: $1(0.2 \%)$ with retrognathia, $54(13.0 \%)$ with tonsillar hypertrophy, and 58 $(14.0 \%)$ with pharyngeal cavity stenosis. The neck and waist circumferences were $(38.46 \pm 3.83)$ and $(97.8 \pm 9.5) \mathrm{cm}$, respectively.

According to the AHI, mild was identified in 88 patients $(21.2 \%)$, moderate in $64(15.4 \%)$, and severe in $263(63.4 \%)$. The mean AHI, respiratory disturbance index (RDI), and respiratory effort related arousal (RERA) of the OSA patients were (42.28 \pm 25.00$),(42.88 \pm 25.19)$, and $(0.59 \pm 1.53) \mathrm{h}^{-1}$. The mean nadir $\mathrm{SaO}_{2}$, average $\mathrm{SaO}_{2}$, oxygen desaturation index (ODI), and percentage of recording time with $\mathrm{SaO}_{2}$ of $<90 \%$ (T90) of the OSA patients were $(70.56 \pm 14.79) \%,(93.01 \pm 3.62) \%,(43.62 \pm 26.17) \mathrm{h}^{-1}$, and $(23.43 \pm 26.72) \%$, respectively. A total of 58 (14.0\%) patients had their nadir $\mathrm{SaO}_{2}$ between $85 \%$ and $90 \%, 74(17.8 \%$ ) between $80 \%$ and $85 \%$, and 280 $(67.5 \%)$ below $80 \%$.

The correlation analysis showed that neck circumference was positively correlated with the AHI $(r=0.341, P<0.001)$ and RDI $(r=0.341, P<0.001)$; the waist circumference was positively correlated with the AHI $(r=0.457, P<0.001)$ and RDI $(r=0.444, P<$ $0.001)$; the BMI was positively correlated with the AHI $(r=0.389, P<0.001)$ and RDI $(r=0.387, P<$ 0.001 ), whereas BMI was negatively correlated with the nadir $\mathrm{SaO}_{2}(r=-0.392, P<0.001)$; the ESS scores was positively correlated with the AHI $(r=0.288, P<$ $0.001)$ and RDI $(r=0.292, P<0.001)$, whereas ESS was negatively correlated with the nadir $\mathrm{SaO}_{2}$ $(r=-0.258, P<0.001)$.

\subsection{Phenotypes of different severities}

The anthropometric data of OSA patients by different severities are shown in Table 1. Symptomatic, clinical, and physical examination data by different severities are shown in Tables 2 and 3. The symptoms of dry mouth $(52.3 \%, 54.7 \%$, and $70.0 \%$, respectively; $P=0.003$ ) and daytime sleepiness $(46.6 \%, 51.6 \%$, and $63.9 \%$, respectively; $P=0.009$ ) were more frequent in the severe OSA patients. The severe OSA patients had higher ESS scores $(6.13 \pm 4.27,6.75 \pm 3.46$, and $8.75 \pm 4.82$, respectively;
Table 1 Anthropometric data of OSA patients by severity

\begin{tabular}{lcccc}
\hline Parameter & Mild & Moderate & Severe & $P$-value \\
\hline Subjects & $88(21.2 \%)$ & $64(15.4 \%)$ & $263(63.4 \%)$ & \\
Age (year) & $45.55 \pm 11.99$ & $47.5 \pm 10.5$ & $45.41 \pm 11.32$ & NS \\
Height $(\mathrm{cm})$ & $168.3 \pm 6.72$ & $168.3 \pm 6.87$ & $170.5 \pm 5.95$ & 0.003 \\
Weight $(\mathrm{kg})$ & $72.92 \pm 10.04$ & $74.89 \pm 10.89$ & $82.03 \pm 11.07$ & $<0.001$ \\
BMI $\left(\mathrm{kg} / \mathrm{m}^{2}\right)$ & $25.81 \pm 3.02$ & $26.37 \pm 2.62$ & $28.19 \pm 3.36$ & $<0.001$ \\
NC $(\mathrm{cm})$ & $36.81 \pm 3.10$ & $37.48 \pm 3.14$ & $39.26 \pm 3.98$ & $<0.001$ \\
WC $(\mathrm{cm})$ & $92.06 \pm 8.39$ & $95.77 \pm 8.85$ & $100.23 \pm 9.04$ & $<0.001$ \\
\hline
\end{tabular}

Data are presented as count (percentage) or mean $\pm \mathrm{SD}(n=415)$. BMI: body mass index; NC: neck circumference; WC: waist circumference; NS: non-significant. " One-way ANOVA

Table 2 Symptomatic and clinical data of OSA patients by severity

\begin{tabular}{lcccc}
\hline Symptom & Mild & Moderate & Severe & $P$-value \\
\hline $\begin{array}{c}\text { Gasping/ } \\
\text { choking }\end{array}$ & $31(35.2 \%)$ & $24(37.5 \%)$ & $116(44.1 \%)$ & $\mathrm{NS}$ \\
$\begin{array}{c}\text { Morning } \\
\text { headaches }\end{array}$ & $14(15.9 \%)$ & $10(15.6 \%)$ & $42(16.0 \%)$ & $\mathrm{NS}$ \\
$\begin{array}{c}\text { Dry mouth } \\
\text { Daytime }\end{array}$ & $46(52.3 \%)$ & $35(54.7 \%)$ & $184(70.0 \%)$ & 0.003 \\
$\quad$ sleepiness & $22(46.6 \%)$ & $33(51.6 \%)$ & $168(63.9 \%)$ & 0.009 \\
$\begin{array}{c}\text { Nocturia } \\
\text { Memory loss }\end{array}$ & $53(60.2 \%)$ & $38(59.4 \%)$ & $161(61.2 \%)$ & $\mathrm{NS}$ \\
$\begin{array}{c}\text { Irritability } \\
\text { ESS scores }\end{array}$ & $34(38.6 \%)$ & $25(39.1 \%)$ & $115(43.7 \%)$ & $\mathrm{NS}$ \\
$\begin{array}{c}\text { Influence of } \\
\text { QOL }\end{array}$ & $28(31.8 \%)$ & $18(28.1 \%)$ & $121(46.0 \%)$ & 0.009 \\
$\begin{array}{c}\text { Influence of } \\
\quad 22(25.0 \%)\end{array}$ & $12(18.8 \%)$ & $87(33.1 \%)$ & 0.049 \\
$\begin{array}{c}\text { work } \\
\text { Influence of } \\
\text { traffic }\end{array}$ & $14(15.9 \%)$ & $6(9.4 \%)$ & $42(16.0 \%)$ & $\mathrm{NS}$ \\
\hline
\end{tabular}

Data are presented as count (percentage) or mean $\pm \mathrm{SD}(n=415)$. ESS: Epworth Sleepiness Scale; QOL: quality of life; NS: nonsignificant. ${ }^{*}$ Chi-squared test or one-way ANOVA

$P<0.001)$ than the mild and moderate OSA patients. The qualities of life $(33.0 \%, 28.1 \%$, and $46.0 \%$, respectively; $P=0.009)$ and work $(25.0 \%, 18.8 \%$, and $33.1 \%$, respectively; $P=0.049$ ) were more frequently influenced in the severe OSA patients. Reflux esophagitis $(2.3 \%, 14.1 \%$, and $5.7 \%$, respectively; $P=0.01)$ was more frequent in the moderate and severe OSA patients.

\subsection{Gender differences in OSA}

The anthropometric and polysomnographic data of the OSA patients by gender are shown in Tables 4 and 5. In the 362 male patients, mild was identified in 
67 patients $(18.5 \%)$, moderate in $53(14.6 \%)$, and severe in $242(66.9 \%)$, according to their AHI. In the 53 female patients, mild was identified in 21 patients $(39.6 \%)$, moderate in $11(20.8 \%)$, and severe in 21 $(39.6 \%)$. Moderate and severe OSA were more frequent in males than in females $\left(\chi^{2}=16.249, P<0.001\right)$. In the 362 male patients, $49(13.5 \%)$ patients had a nadir $\mathrm{SaO}_{2}$ between $85 \%$ and $90 \%, 59(16.3 \%)$ between $80 \%$ and $85 \%$, and $252(69.6 \%)$ below $80 \%$. In 53 female patients, $9(17.0 \%)$ patients had a nadir $\mathrm{SaO}_{2}$ between $85 \%$ and $90 \%, 15(28.3 \%)$ between $80 \%$ and $85 \%$, and $28(52.8 \%)$ below $80 \%$. A difference existed in the distribution of the nadir $\mathrm{SaO}_{2}$ between the genders (Fisher's exact test, $P=0.041$ ).

Table 3 Comorbidities and physical examination data of OSA patients by severity

\begin{tabular}{|c|c|c|c|c|}
\hline Disease & Mild & Moderate & Severe & $P$-value ${ }^{*}$ \\
\hline Hypertension & \multicolumn{2}{|c|}{$24(27.3 \%) 27(42.2 \%)$} & $103(39.2 \%)$ & NS \\
\hline Diabetes mellitus & $7(8.0 \%)$ & $9(14.1 \%)$ & $38(14.4 \%)$ & NS \\
\hline Heart disease & $7(8.0 \%)$ & $9(14.1 \%)$ & $29(11.0 \%)$ & NS \\
\hline $\begin{array}{l}\text { Cerebrovascular } \\
\text { disease }\end{array}$ & $1(1.1 \%)$ & $1(1.6 \%)$ & $5(1.9 \%)$ & NS \\
\hline $\begin{array}{l}\text { Reflux } \\
\text { esophagitis }\end{array}$ & $2(2.3 \%)$ & $9(14.1 \%)$ & $15(5.7 \%)$ & 0.01 \\
\hline Thyroid diseases & $2(2.3 \%)$ & $2(3.1 \%)$ & $11(4.2 \%)$ & NS \\
\hline Rhinitis & $35(39.8 \%)$ & $26(40.6 \%)$ & $98(37.3 \%)$ & NS \\
\hline Pharyngolaryngitis & $39(44.3 \%)$ & $29(45.3 \%)$ & $112(42.6 \%)$ & NS \\
\hline $\begin{array}{l}\text { History of upper } \\
\text { airway surgery }\end{array}$ & $2(2.3 \%)$ & $1(1.6 \%)$ & $11(4.2 \%)$ & NS \\
\hline Retrognathia & $0(0 \%)$ & $0(0 \%)$ & $1(0.4 \%)$ & NS \\
\hline $\begin{array}{l}\text { Tonsillar } \\
\text { hypertrophy }\end{array}$ & $10(11.4 \%)$ & $6(9.4 \%)$ & $38(14.4 \%)$ & NS \\
\hline $\begin{array}{l}\text { Pharyngeal cavity } \\
\text { stenosis }\end{array}$ & $10(11.4 \%)$ & $6(9.4 \%)$ & $42(16.0 \%)$ & NS \\
\hline
\end{tabular}

Table 4 Anthropometric data of OSA patients by gender

\begin{tabular}{lccc}
\hline \multicolumn{1}{c}{ Parameter } & Male & Female & $P$-value $^{*}$ \\
\hline Subjects & $362(87.2 \%)$ & $53(12.8 \%)$ & \\
Age (year) & $44.7 \pm 11.21$ & $52.8 \pm 9.67$ & $<0.001$ \\
Height $(\mathrm{cm})$ & $171.0 \pm 5.3$ & $160.4 \pm 4.9$ & $<0.001$ \\
Weight $(\mathrm{kg})$ & $80.39 \pm 10.99$ & $69.47 \pm 10.74$ & $<0.001$ \\
BMI $\left(\mathrm{kg} / \mathrm{m}^{2}\right)$ & $27.46 \pm 3.24$ & $27.01 \pm 4.04$ & $\mathrm{NS}$ \\
NC $(\mathrm{cm})$ & $39.02 \pm 3.65$ & $34.66 \pm 2.72$ & $<0.001$ \\
WC $(\mathrm{cm})$ & $98.37 \pm 9.08$ & $94.00 \pm 11.25$ & 0.002 \\
\hline
\end{tabular}

Data are presented as count (percentage) or mean $\pm \mathrm{SD}(n=415)$. BMI: body mass index; NC: neck circumference; WC: waist circumference; NS: non-significant. ${ }^{*}$ Independent-sample $t$-test
The symptomatic, clinical and physical examination data by gender are shown in Tables 6 and 7 . Males were affected in their work by OSA more frequently than were females $(P=0.045)$. Thyroid disease was more frequent in female OSA patients $(P=0.003)$.

Table 5 PSG study of OSA patients by gender

\begin{tabular}{cccc}
\hline \multicolumn{1}{c}{ Index } & Male & Female & $P$-value $^{*}$ \\
\hline AHI $\left(\mathrm{h}^{-1}\right)$ & $43.76 \pm 24.33$ & $32.12 \pm 27.34$ & 0.001 \\
$5-15 \mathrm{~h}^{-1}$ & $67(18.5 \%)$ & $21(39.6 \%)$ & \\
$15-30 \mathrm{~h}^{-1}$ & $53(14.6 \%)$ & $11(20.8 \%)$ & $<0.001$ \\
$>30 \mathrm{~h}^{-1}$ & $242(66.9 \%)$ & $21(39.6 \%)$ & \\
RERA $\left(\mathrm{h}^{-1}\right)$ & $0.58 \pm 1.58$ & $0.62 \pm 1.20$ & $\mathrm{NS}$ \\
$\mathrm{RDI}\left(\mathrm{h}^{-1}\right)$ & $44.36 \pm 24.49$ & $32.76 \pm 27.70$ & 0.002 \\
Nadir $\mathrm{SaO}_{2}(\%)$ & $70.27 \pm 14.65$ & $72.58 \pm 15.70$ & $\mathrm{NS}$ \\
$>90 \%$ & $2(0.6 \%)$ & $1(1.9 \%)$ & \\
$85 \%-90 \%$ & $49(13.5 \%)$ & $9(17.0 \%)$ & \\
$80 \%-85 \%$ & $59(16.3 \%)$ & $15(28.3 \%)$ & 0.041 \\
$<80 \%$ & $252(69.6 \%)$ & $28(52.8 \%)$ & \\
Average $\mathrm{SaO}_{2}(\%)$ & $93.00 \pm 3.54$ & $93.06 \pm 4.20$ & $\mathrm{NS}$ \\
ODI $\left(\mathrm{h}^{-1}\right)$ & $44.65 \pm 25.68$ & $36.60 \pm 28.54$ & 0.036 \\
T90 $(\%)$ & $23.78 \pm 26.42$ & $21.10 \pm 28.84$ & $\mathrm{NS}$ \\
\hline
\end{tabular}

Data are presented as count (percentage) or mean $\pm \mathrm{SD}(n=415)$. AHI: apnea-hypopnea index; RERA: respiratory effort related arousal; RDI: respiratory disturbance index; ODI: oxygen desaturation index; T90: percentage of recording time with $\mathrm{SaO}_{2}$ of $<90 \%$; NS: non-significant. " Independent-sample $t$-test or Chisquared test, as appropriate

Table 6 Symptomatic and clinical data of OSA patients by gender

\begin{tabular}{lrcccc}
\hline \multicolumn{1}{c}{ Symptom } & \multicolumn{1}{c}{$B$} & $\mathrm{SE}$ & Wals & \multicolumn{1}{c}{ Sig. $^{*}$} & $\operatorname{Exp}(B)$ \\
\hline Gasping/choking & 0.468 & 0.317 & 2.183 & 0.140 & 1.596 \\
Morning headaches & 0.404 & 0.420 & 0.925 & 0.336 & 1.497 \\
Dry mouth & -0.234 & 0.329 & 0.507 & 0.477 & 0.791 \\
Daytime sleepiness & 0.044 & 0.339 & 0.017 & 0.897 & 1.045 \\
Nocturia & 0.425 & 0.326 & 1.700 & 0.192 & 1.529 \\
Memory loss & 0.183 & 0.338 & 0.292 & 0.589 & 1.201 \\
Irritability & 0.367 & 0.320 & 1.316 & 0.251 & 1.444 \\
ESS scores & -0.052 & 0.040 & 1.738 & 0.187 & 0.949 \\
Influence of QOL & -0.344 & 0.350 & 0.966 & 0.326 & 0.709 \\
Influence of work & -0.905 & 0.451 & 4.027 & 0.045 & 0.405 \\
Influence of traffic & 0.282 & 0.484 & 0.340 & 0.560 & 1.326 \\
Constant & -1.821 & 0.389 & 21.881 & 0.000 & 0.162 \\
\hline
\end{tabular}

$B$ : partial regression coefficient; SE: standard error; Wals: Wald Chi-square; Sig.: significance test; $\operatorname{Exp}(B)$ : odds ratio; ESS: Epworth Sleepiness Scale; QOL: quality of life. " Binary logistic regression analysis 
Table 7 Comorbidities and physical examination data of OSA patients by gender

\begin{tabular}{lrrrrr}
\hline \multicolumn{1}{c}{ Disease } & \multicolumn{1}{c}{$B$} & \multicolumn{1}{c}{ SE } & Wals & Sig. $^{*}$ & $\operatorname{Exp}(B)$ \\
\hline Hypertension & 0.099 & 0.336 & 0.087 & 0.768 & 1.104 \\
Diabetes mellitus & -0.456 & 0.529 & 0.741 & 0.389 & 0.634 \\
Heart disease & 0.481 & 0.474 & 1.030 & 0.310 & 1.618 \\
Cerebrovascular disease & -19.282 & 15072.504 & 0.000 & 0.999 & 0.000 \\
Reflux esophagitis & -0.377 & 0.683 & 0.305 & 0.581 & 0.686 \\
Thyroid diseases & 1.724 & 0.571 & 9.123 & 0.003 & 5.608 \\
Rhinitis & 0.193 & 0.324 & 0.356 & 0.551 & 1.213 \\
Pharyngolaryngitis & -0.109 & 0.321 & 0.115 & 0.735 & 0.897 \\
Post-airway surgery & -0.435 & 1.066 & 0.166 & 0.683 & 0.647 \\
Retrognathia & 21.980 & 40192.970 & 0.000 & 1.000 & 3513413205.792 \\
Tonsillar hypertrophy & -0.628 & 0.532 & 1.395 & 0.238 & 0.534 \\
Pharyngeal cavity stenosis & 0.720 & 0.506 & 2.022 & 0.155 & 2.054 \\
Constant & -2.077 & 0.269 & 59.800 & 0.000 & 0.125 \\
\hline B: parta
\end{tabular}

$B$ : partial regression coefficient; SE: standard error; Wals: Wald Chi-square; Sig.: significance test; $\operatorname{Exp}(B)$ : odds ratio. ${ }^{*}$ Binary logistic regression analysis

\subsection{Age differences in OSA}

The anthropometric and polysomnographic data of the OSA patients by age are shown in Tables 8 and 9. The BMI, neck and waist circumferences were similar in the age groups. In 390 young and middleaged patients, mild OSA was identified in 82 patients $(21.0 \%)$, moderate in $60(15.4 \%)$, and severe in 248 (63.6\%). In 25 elderly patients, mild OSA was identified in 6 patients $(24.0 \%)$, moderate in 4 patients $(16.0 \%)$, and severe in 15 patients $(60.0 \%)$. In 390 young and middle-aged patients, 54 patients (13.8\%) had a nadir $\mathrm{SaO}_{2}$ between $85 \%$ and $90 \%, 66(16.9 \%)$ between $80 \%$ and $85 \%$, and $267(68.5 \%)$ below $80 \%$. In 25 elderly patients, 4 patients $(16.0 \%)$ had a nadir $\mathrm{SaO}_{2}$ between $85 \%$ and $90 \%, 8(32.0 \%)$ between $80 \%$ and $85 \%$, and $13(52.0 \%)$ below $80 \%$.

Table 8 Anthropometric measurements of OSA patients by age

\begin{tabular}{lccc}
\hline \multicolumn{1}{c}{ Parameter } & $\begin{array}{c}\text { Young and } \\
\text { middle-aged }\end{array}$ & Elderly & $P$-value \\
\hline Subjects & $390(94 \%)$ & $25(6 \%)$ & \\
Age (year) & $44.23 \pm 9.83$ & $69.64 \pm 4.64$ & $<0.001$ \\
Height $(\mathrm{cm})$ & $169.87 \pm 6.18$ & $166.48 \pm 7.90$ & 0.009 \\
Weight $(\mathrm{kg})$ & $79.35 \pm 11.50$ & $73.55 \pm 11.45$ & 0.015 \\
BMI $\left(\mathrm{kg} / \mathrm{m}^{2}\right)$ & $26.46 \pm 3.36$ & $26.50 \pm 3.13$ & $\mathrm{NS}$ \\
NC $(\mathrm{cm})$ & $38.49 \pm 3.89$ & $37.96 \pm 2.88$ & $\mathrm{NS}$ \\
WC $(\mathrm{cm})$ & $97.76 \pm 9.52$ & $98.60 \pm 8.89$ & $\mathrm{NS}$ \\
\hline
\end{tabular}

Data are presented as count (percentage) or mean $\pm \mathrm{SD}(n=415)$. BMI: body mass index; NC: neck circumference; WC: waist circumference; NS: non-significant. ${ }^{*}$ Independent-sample $t$-test
Table 9 PSG study of OSA patients by age

\begin{tabular}{cccc}
\hline \multicolumn{1}{c}{ Index } & $\begin{array}{c}\text { Young and } \\
\text { middle-aged }\end{array}$ & Elderly & $P$-value \\
\hline AHI $\left(\mathrm{h}^{-1}\right)$ & $42.75 \pm 25.22$ & $34.87 \pm 20.21$ & $\mathrm{NS}$ \\
$5-15 \mathrm{~h}^{-1}$ & $82(21.0 \%)$ & $6(24.0 \%)$ & \\
$15-30 \mathrm{~h}^{-1}$ & $60(15.4 \%)$ & $4(16.0 \%)$ & $\mathrm{NS}$ \\
$>30 \mathrm{~h}^{-1}$ & $248(63.6 \%)$ & $15(60.0 \%)$ & \\
$\left.\mathrm{RERA}^{-1}\right)$ & $0.601 \pm 1.56$ & $0.392 \pm 0.90$ & $\mathrm{NS}$ \\
$\mathrm{RDI}\left(\mathrm{h}^{-1}\right)$ & $44.37 \pm 25.41$ & $35.26 \pm 20.22$ & $\mathrm{NS}$ \\
$\mathrm{Nadir} \mathrm{SaO}_{2}(\%)$ & $70.34 \pm 14.81$ & $74.00 \pm 14.20$ & $\mathrm{NS}$ \\
$>90 \%$ & $3(0.8 \%)$ & $0(0 \%)$ & \\
$85 \%-90 \%$ & $54(13.8 \%)$ & $4(16.0 \%)$ & $\mathrm{NS}$ \\
$80 \%-85 \%$ & $66(16.9 \%)$ & $8(32.0 \%)$ & \\
$<80 \%$ & $267(68.5 \%)$ & $13(52.0 \%)$ & \\
Average $\mathrm{SaO}_{2}(\%)$ & $93.02 \pm 3.63$ & $92.84 \pm 3.65$ & $\mathrm{NS}$ \\
ODI $\left(\mathrm{h}^{-1}\right)$ & $44.06 \pm 26.44$ & $36.77 \pm 20.64$ & $\mathrm{NS}$ \\
T90 $(\%)$ & $23.57 \pm 26.83$ & $21.36 \pm 25.42$ & $\mathrm{NS}$ \\
\hline
\end{tabular}

Data are presented as count (percentage) or mean \pm SD $(n=415)$. AHI: apnea-hypopnea index; RERA: respiratory effort related arousal; RDI: respiratory disturbance index; ODI: oxygen desaturation index; T90: percentage of recording time with $\mathrm{SaO}_{2}$ of $<90 \%$; NS: non-significant. ${ }^{*}$ Independent-sample $t$-test or Chisquared test, as appropriate

The symptomatic, clinical, and physical examination data by age are shown in Tables 10 and 11 . More elderly OSA patients complained of nocturia $(P=0.004)$. Heart disease was more frequent in the elderly OSA patients $(P=0.014)$. Pharyngolaryngitis presents itself more frequently in young and middleaged OSA patients with a $P$ value that just reached the criteria of statistical significance $(P=0.05)$. 
Table 10 Symptomatic and clinical data of OSA patients by age

\begin{tabular}{lrcccc}
\hline \multicolumn{1}{c}{ Symptom } & \multicolumn{1}{c}{$B$} & SE & Wals & Sig. $^{*}$ & $\operatorname{Exp}(B)$ \\
\hline Gasping/choking & 0.098 & 0.445 & 0.048 & 0.826 & 1.103 \\
Morning & -0.661 & 0.684 & 0.935 & 0.334 & 0.516 \\
headaches & & & & & \\
$\begin{array}{l}\text { Dry mouth } \\
\text { Daytime }\end{array}$ & -0.550 & 0.464 & 1.409 & 0.235 & 0.577 \\
$\quad 0.878$ & 0.519 & 2.864 & 0.091 & 2.407 \\
$\quad$ sleepiness & & & & & \\
Nocturia & 1.275 & 0.446 & 8.185 & 0.004 & 3.578 \\
Memory loss & 0.060 & 0.484 & 0.015 & 0.902 & 1.062 \\
Irritability & 0.642 & 0.451 & 2.023 & 0.155 & 1.900 \\
ESS scores & -0.049 & 0.052 & 0.864 & 0.353 & 0.953 \\
Influence of QOL & -0.139 & 0.486 & 0.082 & 0.775 & 0.870 \\
Influence of work & -0.210 & 0.547 & 0.147 & 0.702 & 0.811 \\
Influence of & 0.302 & 0.595 & 0.257 & 0.612 & 1.352 \\
$\quad$ traffic & & & & & \\
Constant & -3.356 & 0.590 & 32.367 & 0.000 & 0.035 \\
\hline
\end{tabular}

$B$ : partial regression coefficient; SE: standard error; Wals: Wald Chi-square; Sig.: significance test; $\operatorname{Exp}(B)$ : odds ratio; ESS: Epworth Sleepiness Scale; QOL: quality of life. "Binary logistic regression analysis

Table 11 Comorbidities and physical examination data of OSA patients by age

\begin{tabular}{lrrlll}
\hline \multicolumn{1}{c}{ Disease } & \multicolumn{1}{c}{$B$} & \multicolumn{1}{c}{ SE } & Wals & Sig. & $\operatorname{Exp}(B)$ \\
\hline Hypertension & 0.794 & 0.466 & 2.895 & 0.089 & 2.211 \\
Diabetes mellitus & -0.798 & 0.713 & 1.253 & 0.263 & 0.450 \\
Heart disease & 1.290 & 0.525 & 6.025 & 0.014 & 3.632 \\
Cerebrovascular & 1.429 & 0.923 & 2.397 & 0.122 & 4.174 \\
$\quad$ disease & & & & & \\
Reflux esophagitis & 0.744 & 0.666 & 1.249 & 0.264 & 2.105 \\
Thyroid diseases & 0.508 & 0.909 & 0.312 & 0.576 & 1.662 \\
Rhinitis & -0.288 & 0.496 & 0.337 & 0.561 & 0.750 \\
Pharyngolaryngitis & -1.065 & 0.543 & 3.849 & 0.050 & 0.345 \\
Post-airway & -17.969 & 10200.804 & 0.000 & 0.999 & 0.000 \\
surgery & & & & & \\
Retrognathia & -19.995 & 40192.970 & 0.000 & 1.000 & 0.000 \\
Tonsillar & 0.302 & 0.939 & 0.103 & 0.748 & 1.352 \\
$\quad$ hypertrophy & & & & & \\
Pharyngeal cavity & -0.355 & 1.231 & 0.083 & 0.773 & 0.701 \\
$\quad$ stenosis & & & & & \\
Constant & -2.936 & 0.388 & 57.394 & 0.000 & 0.053 \\
\hline$B:$ patian
\end{tabular}

$B$ : partial regression coefficient; SE: standard error; Wals: Wald Chi-square; Sig.: significance test; $\operatorname{Exp}(B)$ : odds ratio." Binary logistic regression analysis

\section{Discussion}

This report is an epidemiological study examining a population of snorers. Our study found that in this population, OSA is the most common condition identified, followed by primary snoring, CSA, and MSA, which are relatively rare. We found that the prevalence of OSA in male subjects is higher, which is in accordance with previous epidemiological studies (Lurie, 2011a). When the subjects were grouped by age, the prevalences of OSA and other types of sleep-disordered breathing conditions were similar in both groups. Previous studies suggested that the prevalence of OSA increased with age (Peppard et al., 2013; Jennum and Riha, 2009), because individuals from the general population were enrolled as subjects in those studies. Our study suggests the prevalence of OSA in male snorers is as high as that in the elderly.

In addition to snoring at night and excessive daytime sleepiness, dry mouth, daytime sleepiness, memory loss, gasping/choking at night, and irritability were common symptoms in OSA patients. Dry mouth, daytime sleepiness, the effect on work, and a reduced quality of life were more frequently reported by severe OSA patients. We found that hypertension was a common comorbidity in OSA patients. OSA contributes to or exacerbates cardiovascular disease (Monahan and Redline, 2011), and hypertension is the most common result (Lurie, 2011b). Through a detailed investigation into the patients' previous medical history, we found that some OSA patients had refractory hypertension, the pathogenesis of which might be related to the chronic intermittent hypoxia experienced by the patients at night (Parati et al., 2014). Therefore, OSA might be a novel target for cardiovascular risk reduction (Monahan and Redline, 2011). A systematic review and meta-analysis suggested that continuous positive airway pressure lowered blood pressure in OSA patients (Montesi et al., 2012). Patients with OSA commonly have comorbid nocturnal gastroesophageal reflux disease (GERD) (Hesselbacher et al., 2014). In our study, we found that reflux esophagitis was more common in moderate and severe OSA patients, and the prevalence of reflux esophagitis did not differ between the genders and age groups. Basoglu et al. (2014) showed that obesity and sleepiness might be related to the prevalence of GERD in OSA patients, which may help explain the results of our study. Their study showed that the severity of OSA did not influence GERD prevalence, whereas female gender might be related to GERD prevalence. They also evaluated GERD comprehensively, whereas, in our study, we focused on reflux esophagitis, a relatively severe form of GERD. In this study, we found a high incidence of rhinitis in the OSA patients. The increased airway 
resistance in rhinitis patients might have a role in the pathogenesis of OSA. Parikh et al. (2014) found that in patients with OSA and rhinitis, the ESS score is associated with the symptom severity of rhinitis. Additionally, we found that pharyngolaryngitis was a common comorbidity in OSA patients. A bidirectional relationship might exist between OSA and pharyngolaryngitis. Pharyngolaryngitis might increase upper airway resistance. Conversely, repeated collapse and return of the upper airway in OSA patients might induce pharyngolaryngitis. Local anatomical abnormalities, such as tonsillar hypertrophy, pharyngeal cavity stenosis, and retrognathia, could cause mechanical obstruction of the upper airway (Azagra-Calero et al., 2012). In OSA patients with anatomical abnormalities of the upper airway, three-dimensional reconstruction of the upper airway by multi-slice spiral computed tomography is proposed. If necessary, a careful surgical assessment is performed. In our study, we found a relatively low incidence of anatomical abnormalities in the OSA patients. Consistent with our findings, Azagra-Calero et al. (2012) suggested that the main cause of OSA is a reduction of the expansion forces of the pharyngeal dilator muscles, as in situations of genioglossal muscle dysfunction, and between the inspiratory activity of the muscle and the respiratory effort, which play an important role in the progression of the disease.

PSG monitoring is a labor-intensive and expensive test conducted in a limited number of facilities, which have many patients waiting for appointments. In our study, the correlation analysis revealed that the neck circumference, waist circumference, and BMI were positively correlated with the AHI/RDI and that the BMI was negatively correlated with the nadir $\mathrm{SaO}_{2}$. The analysis of the patients with different disease severity showed that severe patients had a greater BMI as well as larger neck and waist circumferences. Chang et al. (2014) showed that the neck circumference could be a useful clinical predictor of OSA in Chinese patients. Neck circumference, waist circumference, and BMI might be indicators of the severity of OSA and could be used to screen for OSA in the general population. ESS is widely used in the evaluation of patients with sleep-disordered breathing because of its simplicity and convenience (Damiani et al., 2013). We found that ESS scores were positively correlated with AHI/RDI, whereas they were nega- tively correlated with the nadir $\mathrm{SaO}_{2}$ and were significantly increased in severe OSA patients; therefore, the ESS score might be another indicator of severity. For the patients with a high possibility of severe OSA, full-night PSG should be conducted as early as possible.

The proportion of OSA patients with an AHI of $>15$ (moderate to severe) or with a nadir $\mathrm{SaO}_{2}$ of $<80 \%$ was higher in males. The AHI/ADI and ODI were higher in male OSA patients. Consistent with the study of Sforza et al. (2011), our study suggested that male OSA patients had more severe OSA. Consistent with our findings, Banhiran et al. (2014) showed that male gender was a good predictor for moderate to severe OSA. We found that daily work was more frequently affected by OSA in males. No specific quantitative indicators were adopted in this study. Moreover, the types of work might be affected by gender, which could influence the results. A higher incidence of thyroid disease, predominantly Graves' disease and hypothyroidism, was found in the female OSA patients. It is unclear whether there is an intrinsic relationship between the pathogenesis of OSA and Graves' disease. A higher incidence of Graves' disease in females might partly explain the results of our study. There might be an interaction between hypothyroidism and OSA. Hypothyroidism could cause OSA, which might be related to structural change of the upper airway and myopathy associated with hypothyroidism. OSA could cause hypothyroidism through its complicated influence on endocrine and metabolic functions. Ozcan et al. (2014) showed that the incidence of hypothyroidism in OSA patients was $12.77 \%$.

We found that the severity of OSA was similar between the elderly and non-elderly OSA patients. Nocturia was more common in the elderly. The result was consistent with the study of Raheem et al. (2014) showing that age is a predictor of nocturia in OSA patients. IRomero et al. (2010) showed that nocturia appeared comparable to snoring as a screening tool for OSA. The mechanism is unknown, and increased secretion of atrial natriuretic peptide (ANP) might be involved (Raheem et al., 2014). ANP acts in the kidneys to increase the excretion of sodium and thus the drainage of water. The workload increases in OSA patients. Physiologically, the compensatory capacity of the kidneys decreases with the increase of age. 
Therefore, renal function tends to be impaired in elderly OSA patients. We found that the incidence of heart disease was higher in elderly OSA patients. Many cardiovascular diseases, such as hypertension, coronary heart disease, heart failure, and arrhythmia, could be caused or aggravated by OSA, and the coexistence of OSA and cardiovascular diseases increases the mortality rate (Kasai et al., 2012). Oxidative stress, inflammation, and endothelial dysfunction induced by chronic intermittent hypoxia, a main pathophysiological change in OSA, are important mechanisms underlying these lesions (Kasai et al., 2012; Prabhakar and Semenza, 2012; Badran et al., 2014). Therefore, for OSA patients with cardiovascular diseases, continuous positive airway pressure (CPAP) therapy should be initiated as early as possible. The incidence of pharyngolaryngitis was higher in young and middle-aged OSA patients, although the cause is unknown. We suggest that OSA patients should receive a careful diagnosis and treatment for pharyngolaryngitis.

In this study, we found that OSA is the most common sleep-disordered breathing condition among snorers. Neck circumference, waist circumference, and BMI are good candidates as indicators to assess the severity of disease. Male OSA patients had more severe conditions, and their work was influenced more frequently. The severity of OSA was similar in young, middle-aged, and elderly OSA patients. The incidences of nocturia and heart disease were higher in elderly OSA patients. The lack of quantitative indicators in the evaluation of some clinical features and a detailed classification of some comorbidities is the limitation of our study, which should be addressed in a future study.

\section{Acknowledgements}

We sincerely thank Prof. Li-na ZHANG (Department of Epidemiology, Ningbo University School of Medicine, China) for her excellent assistance in the statistical analysis.

\section{Compliance with ethics guidelines}

Chuan SHAO, Jing-bo JIANG, Hong-cheng WU, Shi-bo WU, Bi-yun YU, and Yao-dong TANG declare that they have no conflict of interest.

All procedures followed were in accordance with the ethical standards of the responsible committee on human experimentation (institutional and national) and with the Helsinki Declaration of 1975, as revised in 2008 (5). Informed consent was obtained from all patients for being included in the study. Additional informed consent was obtained from all patients for whom identifying information is included in this article.

\section{References}

Azagra-Calero, E., Espinar-Escalona, E., Barrera-Mora, J.M., et al., 2012. Obstructive sleep apnea syndrome (OSAS). Review of the literature. Med. Oral Patol. Oral Cir. Bucal, 17(6):e925-e929. [doi:10.4317/medoral.17706]

Badran, M., Ayas, N., Laher, I., 2014. Insights into obstructive sleep apnea research. Sleep Med., 15(5):485-495. [doi:10. 1016/j.sleep.2014.01.009]

Banhiran, W., Junlapan, A., Assanasen, P., et al., 2014. Physical predictors for moderate to severe obstructive sleep apnea in snoring patients. Sleep Breath., 18(1):151158. [doi:10.1007/s11325-013-0863-y]

Basoglu, O.K., Vardar, R., Tasbakan, M.S., et al., 2014. Obstructive sleep apnea syndrome and gastroesophageal reflux disease: the importance of obesity and gender. Sleep Breath., in press. [doi:10.1007/s11325-014-1051-4]

Chang, E.T., Yang, M.C., Wang, H.M., et al., 2014. Snoring in a sitting position and neck circumference are predictors of sleep apnea in Chinese patients. Sleep Breath., 18(1):133136. [doi:10.1007/s11325-013-0860-1]

Damiani, M.F., Quaranta, V.N., Falcone, V.A., et al., 2013. The Epworth Sleepiness Scale: conventional self vs physician administration. Chest, 143(6):1569-1575. [doi:10. 1378/chest.12-2174]

de Backer, W., 2013. Obstructive sleep apnea/hypopnea syndrome. Panminerva Med., 55(2):191-195.

Epstein, L.J., Kristo, D., Strollo, P.J.Jr., et al., 2009. Clinical guideline for the evaluation, management and long-term care of obstructive sleep apnea in adults. J. Clin. Sleep Med., 5(3):263-276.

Hesselbacher, S., Subramanian, S., Rao, S., et al., 2014. Selfreported sleep bruxism and nocturnal gastroesophageal reflux disease in patients with obstructive sleep apnea: relationship to gender and ethnicity. Open Respir. Med. J., 22(8):34-40. [doi:10.2174/1874306401408010034]

Jennum, P., Riha, R.L., 2009. Epidemiology of sleep apnoea/ hypopnoea syndrome and sleep-disordered breathing. Eur. Respir. J., 33(4):907-914. [doi:10.1183/09031936.00180 108]

Jordan, A.S., McSharry, D.G., Malhotra, A., 2014. Adult obstructive sleep apnoea. Lancet, 383(9918):736-747. [doi:10.1016/S0140-6736(13)60734-5]

Kasai, T., Floras, J.S., Bradley, T.D., 2012. Sleep apnea and cardiovascular disease: a bidirectional relationship. Circulation, 126(12):1495-1510. [doi:10.1161/CIRCULATIONAHA. 111.070813]

Lurie, A., 2011a. Obstructive sleep apnea in adults: epidemiology, clinical presentation, and treatment options. In: Borer, J.S. (Ed.), Advances in Cardiology. Karger, Basel, p.1-42. [doi:10.1159/000327660]

Lurie, A., 2011b. Obstructive sleep apnea in adults: cardiovascular disorders associated with obstructive sleep apnea. 
In: Borer, J.S. (Ed.), Advances in Cardiology. Karger, Basel, p.197-266. [doi:10.1159/000325110]

Monahan, K., Redline, S., 2011. Role of obstructive sleep apnea in cardiovascular disease. Curr. Opin. Cardiol., 26(6):541-547. [doi:10.1097/HCO.0b013e32834b806a]

Montesi, S.B., Edwards, B.A., Malhotra, A., et al., 2012. The effect of continuous positive airway pressure treatment on blood pressure: a systematic review and meta-analysis of randomized controlled trials. J. Clin. Sleep Med., 8(5): 587-596. [doi:10.5664/jcsm.2170]

Ozcan, K.M., Selcuk, A., Ozcan, I., et al., 2014. Incidence of hypothyroidism and its correlation with polysomnography findings in obstructive sleep apnea. Eur. Arch. Otorhinolaryngol., 271(11):2937-2941. [doi:10.1007/s00405014-2962-1]

Parati, G., Ochoa, J.E., Bilo, G., et al., 2014. Obstructive sleep apnea syndrome as a cause of resistant hypertension. Hypertens. Res., 37(7):601-613. [doi:10.1038/hr.2014.80]

Parikh, N.G., Junaid, I., Sheinkopf, L., et al., 2014. Clinical control in the dual diagnosis of obstructive sleep apnea syndrome and rhinitis: a prospective analysis. Am. $J$. Rhinol. Allergy, 28(1):e52-e55. [doi:10.2500/ajra.2014. 28.3977]

Peppard, P.E., Young, T., Barnet, J.H., et al., 2013. Increased prevalence of sleep-disordered breathing in adults. Am. J. Epidemiol., 177(9):1006-1014. [doi:10.1093/aje/kws342]

Prabhakar, N.R., Semenza, G.L., 2012. Adaptive and maladaptive cardiorespiratory responses to continuous and intermittent hypoxia mediated by hypoxia-inducible factors 1 and 2. Physiol. Rev., 92(3):967-1003. [doi:10. 1152/physrev.00030.2011]

Raheem, O.A., Orosco, R.K., Davidson, T.M., et al., 2014. Clinical predictors of nocturia in the sleep apnea population. Urol. Ann., 6(1):31-35. [doi:10.4103/0974-7796.127019]

Romero, E., Krakow, B., Haynes, P., et al., 2010. Nocturia and snoring: predictive symptoms for obstructive sleep apnea. Sleep Breath., 14(4):337-343. [doi:10.1007/s11325-009-
0310-2]

Sforza, E., Chouchou, F., Collet, P., et al., 2011. Sex differences in obstructive sleep apnoea in an elderly French population. Eur. Respir. J., 37(5):1137-1143. [doi:10. 1183/09031936.00043210]

\section{中文概要}

题 目：490 例因鼾症就诊者临床特点和多导睡眠监测结 果分析

目 的: 探讨因鼾症就诊者临床特点与多导睡眠监测 (PSG) 结果及其相关性, 加深对鼾症和阻塞性 睡眠呼吸暂停综合征（OSA）的理解。

创新点: 较为全面地评估了因鼾症就诊者的临床特点和多 导睡眠监测结果, 比较了不同严重程度的 OSA 患 者的临床特征, 同时分析了性别和年龄差异对 OSA 患者临床特点和 PSG 结果的影响, 有助于进 一步全面深刻地理解鼾症和 OSA 的流行病学和 临床特征。

方 法: 对因夜间睡眠时打鼾就诊的 490 名患者进行病史 采集、Epworth 嗜睡评分 (ESS)、体格检查 (BMI) 和整夜多导睡眠监测（PSG）。分析 OSA 患者临 床症状、BMI、主观嗜睡与呼吸暂停低通气指数 (AHI) 、夜间低氧等的相关关系, 比较不同性 别、不同年龄组 OSA 患者临床症状和病情严重程 度的差异。

结 论: 因鼾症就诊者中 OSA 患者比例最高, 且多数为 中重度 OSA。OSA 患者 ESS 评分、BMI 与病情 严重程度有较好的相关性。男性 OSA 患者病情较 女性重。老年 OSA 患者易出现夜尿增多, 合并心 脏病比例增高。

关键词: 阻塞性睡眠呼吸暂停; 性别; 老年; 低氧; 鼾症 